\title{
Impact of Restless Legs Syndrome on the Sleep Quality in Chronic Obstructive Pulmonary Disease
}

\author{
Erdal İn ${ }^{1}$, Teyfik Turgut ${ }^{1}$, Cengiz Özdemir ${ }^{2}$
}

${ }^{1}$ Department of Chest Diseases, Frrat University School of Medicine, Elazığ, Turkey

${ }^{2}$ Sleep Disorders Center, Yedikule Chest Diseases and Chest Surgery Training and Research Hospital, İstanbul, Turkey

\begin{abstract}
Objective: It is well known that various sleep disorders are common in cases of chronic obstructive pulmonary disease (COPD). However, restless legs syndrome (RLS) has not been extensively studied in these patients. The aim of the current study was to investigate the prevalence of RLS and its impact on sleep quality in patients with COPD.
\end{abstract}

Methods: The study included a total of 50 patients with COPD with a mean age of $67.2 \pm 7.7$ years; 39 (78\%) were male. The RLS diagnosis was made based on the questionnaire items standardized by the International RLS study group. Dyspnea severity (mMRC), quality of life (CAT), sleep quality [Pittsburgh sleep quality index (PSQI)], and daytime sleepiness [Epworth sleepiness scale (ESS)] were evaluated using certain specific questionnaires. The subjects were studied in two groups: RLS-positive and RLS-negative groups.

Results: In the study population, RLS was detected in 17 (34\%) patients. It was found that the RLS-positive subjects had a longer disease duration $(\mathrm{p}=0.006)$, a higher hospital admission rate $(\mathrm{p}=0.008)$, and lower spirometric values $(\mathrm{p}=0.023$ for FVC; $\mathrm{p}=0.001$ for FEV $)$. The CAT score was significantly higher in the RLS-positive group ( $p=0.019)$. The RLS-positive group had higher PSQI and ESS scores $(p<0.001$ for both). There were negative correlations between PSQI, ESS scores, and spirometric measures (FVC and FEV), whereas PSQI and ESS scores had positive correlations with disease duration, $\mathrm{MMRC}$, and CAT scores.

Conclusion: In our study, it was observed that RLS is a common condition in patients with COPD. As the duration and severity of COPD increases, RLS becomes more prevalent and sleep quality deteriorates.

Keywords: Chronic obstructive pulmonary disease, restless legs syndrome, sleep quality

\section{INTRODUCTION}

Restless legs syndrome (RLS), which is also known as Willis-Ekbom disease, is a chronic and progressive sensorimotor disorder that often presents with an irresistible urge to move the legs and primarily involves sensorial symptoms. Epidemiological studies have revealed that its prevalence in the general population ranges between 5\% and 15\% (1).The frequency of RLS is high in advanced ages and particularly in women, but symptoms can begin in childhood or adulthood, and prevalence significantly increases with age (2). RLS is accepted to be an idiopathic disease. However, it is known that its frequency increases in association with iron deficiency anemia, pregnancy, end-stage renal failure, neuropathy, rheumatoid arthritis, and Parkinson's disease $(3,4)$. The pathophysiology of RLS has not been wellunderstood, but the evidence obtained so far suggests that it is associated with abnormalities in the metabolisms of iron/transferrin and dopamine (5). Because symptoms are usually seen at night, RLS patients generally have sleep disorders. Sleep disorders are the primary morbidity of the disease and cause a decrease in the quality of life (6). The diagnosis of RLS is established considering the patient's medical history; polysomnographic examination is not required. The diagnostic criteria were determined by the International Restless Legs Syndrome Study Group (IRLSSG), with the final diagnostic criteria comprising four key items and supportive criteria (3).

Chronic obstructive pulmonary disease (COPD) is a common respiratory disease that affects millions of people across the world and is characterized by progressive and usually irreversible airway ob- 
struction (7). Poor quality sleep and sleep disorders are frequently seen in COPD patients. Studies show that sleep disorders, including having difficulty in falling and staying asleep, insomnia, waking in the night, hypersomnia, obstructive sleep apnea syndrome, and nocturnal oxygen desaturation, are frequently found in these patients (8). In the literature, there are a few studies investigating the frequency of RLS in COPD patients (9-12). While an increased frequency of RLS was detected compared to the normal population in three studies (9-11), no statistically significant difference was found in another study conducted on COPD patients without an additional disease (12).

In this cross-sectional study, it was aimed to investigate the prevalence of RLS in COPD patients without a comorbid disease and the effect of RLS on sleep quality, daytime sleepiness, and life quality.

\section{METHODS}

The study included 50 COPD patients with no additional respiratory disease, pulmonary-extrapulmonary malignancy, or peripheral vascular disease, who were admitted to the Outpatient Clinic of Chest Diseases in Firat University Medical Faculty between October 01, 2014 and April 01, 2015. Patients with scleroderma, diabetes mellitus, Parkinson's disease, chronic renal failure, hepatic encephalopathy, peripheral neuropathy, dysmotility, a high level of ferritin, or a low level of iron were excluded from the study. Furthermore, patients receiving a dopamine antagonist, antidepressant, caffeine, alcohol, cocaine, and/or amphetamine were also excluded. All patients included in the study were informed about the study, and their written informed consents were obtained. The study was conducted in accordance with the Declaration of Helsinki, and ethical approval was received from the Local Ethics Committee of FIrat University.

Routine laboratory tests (hemogram, sedimentation, and biochemical analysis), pulmonary function tests (PFT), and arterial blood gases (ABG) measurements were performed for all the patients participated in the study. In addition, the duration of disease, smoking history, the number of exacerbation within the last one year, severity of dyspnea according to the Modified British Medical Research Council (mMRC) dyspnea scale, and quality of life according to the COPD Assessment Test (CAT) scale (ranging from 0 to 40) were recorded. Before evaluation, the patients were divided into four groups by using the new staging system recommended by GOLD (Global Initiative for Chronic Obstructive Lung Disease) in 2013 (13).

All the patients who were included in the study for the diagnosis of RLS were given an RLS questionnaire comprising four questions, which was formulated by IRLSSG and updated in 2003 (3). According to this, the patients with 1) An urge to move the legs, accompanied by a disturbing or unpleasant sensation in the legs, 2) An urge to move the legs that increases during the periods of rest or inactivity such as lying and sitting, 3) An urge to move the legs that is relieved by movements such as walking and stretching or at least decreases during the activity, or 4) An urge to move the legs, which is more severe at night than during daytime or occurs only at night were diagnosed with RLS. In the study, questionnaire items, the validity and reliability of which were proven in Turkish, were used (14). For the determination of disease severity, an assessment scale, which was standardized by IRLSSG for evaluating the severity of RLS, was utilized (15).
The Pittsburgh Sleep Quality Index (PSQI) was used for evaluating the sleep qualities of the patients. PSQI is a questionnaire that assesses sleep quality through questions asked under seven headings-subjective sleep quality, sleep latency, sleep duration, habitual sleep efficiency, sleep disturbance, use of sleep medication, and daytime dysfunction. Excessive daytime sleepiness was evaluated through the Epworth Sleepiness Scale (ESS). This questionnaire consists of eight questions related to sleepiness; scores of 10 and above show excessive daytime sleepiness in ESS (16). Turkish versions of both questionnaires were standardized by Ağargün et al. (17) and İzci et al. (18), respectively.

\section{Statistical Analysis}

The data obtained were statistically analyzed by using IBM SPSS Statistics 21 (Statistical Product and Service Solutions 21.0 version, authorization code: d91314f638c364094170; Armonk, NY, USA) software. The values were presented as mean \pm standard deviation. Student's t-test was used for comparing scores obtained from the questionnaires applied to the groups, for the demographic features of the patients, the biochemical parameters, and the ABD and PFT results. On the other hand, the Chi-square $\left(X^{2}\right)$ test was employed for the comparison of numerical values between the groups. For correlation analysis, Pearson correlation test was used. Values of $p<0.05$ were accepted to be statistically significant.

\section{RESULTS}

Of 50 COPD patients included in the study, 39 (78\%) were men and the mean age was $67.2 \pm 7.7$ years. RLS was detected in 17 (34\%) of 50 patients. There was no statistically significant difference between

Table 1. Demographic and laboratory findings of COPD patients with and without RLS

\begin{tabular}{|c|c|c|c|}
\hline & $\begin{array}{l}\text { RLS (+) } \\
(34 \%)\end{array}$ & $\begin{array}{l}\text { RLS (-) } \\
(66 \%)\end{array}$ & $\mathbf{p}$ \\
\hline Age (year) * & $64.8 \pm 8.0$ & $68.4 \pm 7.4$ & 0.129 \\
\hline Gender, male, n (\%) & $15(88.2)$ & $24(72.7)$ & 0.210 \\
\hline BMI $\left(\mathrm{kg} / \mathrm{m}^{2}\right)^{*}$ & $26.1 \pm 4.4$ & $26.5 \pm 5.7$ & 0.812 \\
\hline Smoking (pack-year) * & $48.0 \pm 21.4$ & $33.6 \pm 26.4$ & 0.059 \\
\hline Duration of disease (year) * & $10.0 \pm 3.0$ & $6.8 \pm 4.0$ & 0,006 \\
\hline $\begin{array}{l}\text { Number of hospitalization } \\
\text { (last one year) * }\end{array}$ & $2.7 \pm 1.1$ & $1.7 \pm 1.1$ & 0,008 \\
\hline Hemoglobin $(\mathrm{mg} / \mathrm{dL})$ * & $14.3 \pm 1.4$ & $13.9 \pm 1.4$ & 0.403 \\
\hline Hematocrit (\%)* & $45.5 \pm 5.7$ & $43.4 \pm 5.7$ & 0.234 \\
\hline Platelet $\left(\times 10^{9} / \mathrm{L}\right) *$ & $260.2 \pm 78.3$ & $263.3 \pm 84.5$ & 0.903 \\
\hline Sedimentation $(\mathrm{mm} / \mathrm{h}) *$ & $23.6 \pm 16.7$ & $25.5 \pm 14.3$ & 0.683 \\
\hline Glucose $(\mathrm{mg} / \mathrm{dL})^{*}$ & $104.9 \pm 20.4$ & $108.7 \pm 18.0$ & 0.501 \\
\hline Creatinine $(\mathrm{mg} / \mathrm{dL}) *$ & $1.0 \pm 0.21$ & $1.1 \pm 0.26$ & 0.983 \\
\hline $\mathrm{Fe}(\mu \mathrm{g} / \mathrm{dL}) *$ & $76.1 \pm 9.6$ & $79.3 \pm 14.6$ & 0.418 \\
\hline $\mathrm{FeBC}(\mu \mathrm{g} / \mathrm{dL}) *$ & $36.9 \pm 2.1$ & $39.6 \pm 2.5$ & 0.492 \\
\hline Ferritin $(\mathrm{ng} / \mathrm{mL}) *$ & $7.2 \pm 4.8$ & $10.6 \pm 4.0$ & 0.274 \\
\hline
\end{tabular}

*Mean \pm Standard deviation

BMI: Body mass index; COPD: chronic obstructive pulmonary disease; CRP: C-reactive protein; Fe: iron; FeBC: iron-binding capacity; RLS: restless legs syndrome 


\begin{tabular}{|c|c|c|c|}
\hline & $\begin{array}{c}\text { RLS (+) } \\
(34 \%)\end{array}$ & $\begin{array}{l}\text { RLS (-) } \\
(66 \%)\end{array}$ & p \\
\hline \multicolumn{4}{|l|}{ PFT } \\
\hline FVC (\%)* & $49.0 \pm 11.2$ & $59.1 \pm 15.6$ & 0.023 \\
\hline $\mathrm{FEV}_{1}(\%)^{*}$ & $32.9 \pm 7.2$ & $47.5 \pm 15.0$ & 0.001 \\
\hline $\mathrm{FEV}_{1} / \mathrm{FVC}^{*}$ & $52.5 \pm 9.2$ & $59.1 \pm 9.2$ & 0.035 \\
\hline $\operatorname{PEF}(\%)^{*}$ & $34.8 \pm 10.6$ & $46.3 \pm 13.6$ & 0.006 \\
\hline \multicolumn{4}{|l|}{$A B G$} \\
\hline $\mathrm{Ph}^{*}$ & $7.41 \pm 0.04$ & $7.39 \pm 0.05$ & 0.266 \\
\hline $\mathrm{PaO}_{2}(\mathrm{mmHg})^{*}$ & $54.0 \pm 7.4$ & $59.5 \pm 12.9$ & 0.063 \\
\hline $\mathrm{SaO}_{2}(\%)^{*}$ & $84.4 \pm 7.3$ & $86.8 \pm 7.6$ & 0.286 \\
\hline $\mathrm{PaCO}_{2}(\mathrm{mmHg})^{*}$ & $42.4 \pm 9.3$ & $43.8 \pm 9.0$ & 0.612 \\
\hline $\mathrm{HCO}_{3}(\mathrm{meq} / \mathrm{L})^{*}$ & $25.8 \pm 4.7$ & $25.6 \pm 3.3$ & 0.882 \\
\hline \multicolumn{4}{|c|}{ Scales /Questionnaires } \\
\hline $\mathrm{mMRC}^{*}$ & $3.2 \pm 0.7$ & $2.9 \pm 0.7$ & 0.097 \\
\hline $\mathrm{CAT}^{*}$ & $25.3 \pm 6.1$ & $19.8 \pm 8.5$ & 0.019 \\
\hline PSQI* & $13.2 \pm 2.6$ & $7.6 \pm 3.5$ & $<0.001$ \\
\hline ESS* & $11.4 \pm 4.5$ & $6.3 \pm 3.2$ & $<0.001$ \\
\hline \multicolumn{4}{|c|}{ *Mean \pm Standard deviation } \\
\hline \multicolumn{4}{|c|}{$\begin{array}{l}\text { ABG: Arterial blood gases; } \mathrm{CAT} \text { : COPD Assessment Test; } \mathrm{ESS} \text { : Epworth } \\
\text { Sleepiness Scale; } \mathrm{FEV}_{1} \text { : forced expiratory volume in } 1 \text { second; } \mathrm{FVC} \text { : } \\
\text { forced vital capacity; } \mathrm{HCO}_{3} \text { : bicarbonate; } \mathrm{mMRC} \text { : Modified } \mathrm{British} \text { Medical } \\
\text { Research Council; } \mathrm{PaCO}_{2} \text { : partial carbon dioxide pressure; } \mathrm{PaO}_{2}: \text { partial } \\
\text { oxygen pressure; } \mathrm{PEF} \text { : peak expiratory flow; PFT: pulmonary function tests; } \\
\text { PSQI: Pittsburg Sleep Quality Index; } \mathrm{SaO}_{2} \text { : oxyhemoglobin saturation }\end{array}$} \\
\hline
\end{tabular}

patients with and without RLS in terms of age, gender, body mass index, and smoking. However, the duration of disease and the number of hospitalization within the last 1 year were significantly higher in patients with RLS than in patients without $\operatorname{RLS}(p=0.006$ and $p=0.008$, respectively).

In the evaluation of laboratory examinations in patients, no statistically significant differences were observed between the two groups with regard to hemoglobin, platelet count, sedimentation, glucose, creatinine, iron, iron-binding capacity, and ferritin values. The demographic features and laboratory findings of patients with and without RLS are given in Table 1.

The patients were evaluated for PFT values, and it was found that the values of FVC, $\mathrm{FEV}_{1}, \mathrm{FEV}_{1} / \mathrm{FVC}$, and PEF were significantly lower in patients with RLS ( $p=0.023, p=0.001, p=0.035$, and $p=0.006$, respectively). In terms of $A B G$ values, no statistically significant difference was observed between the groups (Table 2). When patients were staged in accordance with the spirometric GOLD staging system, 11 patients (22\%) were found to be stage 2, 29 (58\%) were stage 3, and 10 (20\%) were stage 4 .

Patients were evaluated with the mMRC dyspnea scale, which measures the severity of dyspnea, and the CAT test, which assesses the health state; and no significant difference was found between the RLS and non-RLS groups in terms of mMRC dyspnea scale. Howev-
Table 3. The correlations between the scores of the Pittsburgh sleep quality index and the Epworth sleepiness scale and various parameters in COPD patients

\begin{tabular}{|l|c|c|c|c|}
\multirow{2}{*}{} & \multicolumn{2}{|c|}{ PSQI } & \multicolumn{2}{c|}{ ESS } \\
\hline Duration of disease & 0.298 & 0.035 & 0.332 & 0.019 \\
$\mathrm{PaO}_{2}$ & -0.501 & $<0.001$ & -0.260 & 0.068 \\
$\mathrm{SaO}_{2}$ & -0.350 & 0.013 & -0.246 & 0.085 \\
FVC & -0.505 & $<0.001$ & -0.314 & 0.026 \\
FEV & -0.540 & $<0.001$ & -0.272 & 0.056 \\
mMRC $^{*}$ & 0.388 & 0.005 & 0.294 & 0.038 \\
CAT & 0.597 & $<0.001$ & 0.409 & 0.003 \\
\hline
\end{tabular}

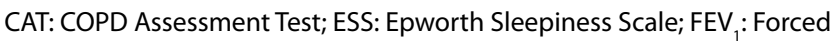
expiratory volume in 1 second; FVC: forced vital capacity; mMRC: Modified British Medical Research Council; $\mathrm{PaO}_{2}$ : partial oxygen pressure; PSQI: Pittsburg Sleep Quality Index; $\mathrm{SaO}_{2}$ : oxyhemoglobin saturation

\begin{tabular}{|c|c|c|c|}
\hline $\mathrm{FEV}_{1}<50 \%$ & $\begin{array}{c}C \\
2(4 \%)\end{array}$ & $\begin{array}{c}D \\
37(74 \%)\end{array}$ & $\begin{array}{l}\text { Exacerbation/ } \\
\text { Hospitalization } \\
\qquad 2 \text { / } \geq 1\end{array}$ \\
\hline \multirow[t]{2}{*}{$\mathrm{FEV}_{1} \geq 50 \%$} & $\begin{array}{l}A \\
0\end{array}$ & $\begin{array}{c}\text { B } \\
11(22 \%)\end{array}$ & \multirow[t]{2}{*}{$0-1 / 0$} \\
\hline & $\begin{array}{l}0-1 \\
<10\end{array}$ & $\begin{array}{cl}\mathrm{mMRC} & \geq 2 \\
\text { CAT } & \geq 10\end{array}$ & \\
\hline
\end{tabular}

Figure 1. Distribution of patients according to the 2013 GOLD classification (13)

CAT: COPD Assessment Test; FEV : Forced expiratory volume in 1 second; mMRC: Modified British Medical Research Council

er, the results of CAT test were significantly higher in the RLS group $(\mathrm{p}=0.019)$ (Table 2).

In the analysis of the scores of the questionnaires that evaluated sleep quality (PSQI) and daytime sleepiness (ESS), both PSQI and ESS scores were detected to be significantly higher in the group with RLS than in the group without RLS ( $p<0.001$ for both questionnaires) (Table 2 ).

The patients with RLS were evaluated in terms of the disease severity through RLS severity questionnaire, and the mean score of patients was found to be $22.2 \pm 6.9$.

The patients were classified according to the updated COPD staging system, and it was revealed that 11 patients (22\%) were in the $\mathrm{B}$ group, 2 patients (4\%) were in the $\mathrm{C}$ group, and 37 patients $(74 \%)$ were in the $D$ group (Figure 1).

Correlation analysis was performed for all the patients included in the study, and a positive correlation was found between the duration 
of disease and PSQI and ESS. Considering the relationship between the values of $A B G$ and PFT and sleep quality, there was a negative correlation between PSQI values and both the levels of $\mathrm{PaO}_{2}$ and $\mathrm{SaO}_{2}$ and the levels of FVC and $\mathrm{FEV}_{1}$. While a negative correlation was observed between FVC and ESS, no correlation was found between the values of $\mathrm{PaO}_{2}, \mathrm{SaO}_{2}$, and $\mathrm{FEV}_{1}$ and ESS. On the other hand, positive correlations were detected between the values of $\mathrm{mMRC}$ and CAT and the scores of PSQI and ESS. However, there was no correlation between the duration and severity of COPD and the severity of RLS. The correlation values of patients are shown in Table 3.

\section{DISCUSSION}

The data obtained in our study demonstrated that RLS with COPD was a highly frequent disorder that affected more than $1 / 3$ patients. Moreover, it was found that as long as the duration and severity of COPD increased, the incidence of RLS increased and sleep quality was impaired.

Epidemiological studies show that the prevalence of RLS in the general population varies between $5 \%$ and $15 \%$. However, it is known that RLS prevalence increases in parallel with age $(1,2)$. In a study conducted in Turkey with 3234 participants, the prevalence of RLS was found to be $3.19 \%$ (14). In literature, there is a study investigating the relationship between COPD and RLS. Kaplan et al. (9) investigated the prevalence of RLS in COPD patients and the relationship between the clinical/laboratory findings of COPD and RLS and they found RLS in 39 (29.1\%) of 134 COPD patients. When patients were divided into two groups as patients with and without RLS, it was observed that the duration of COPD was longer in the RLS group and airway obstruction, hypercapnia, and hypoxia were more prominent. In another study evaluating 84 COPD patients and 110 healthy control patients regardless of gender, the prevalence of RLS in COPD patients (36.8\%) was found to be significantly higher than in the control group (11.8\%). In this study, in which comorbid diseases related to symptomatic RLS were not ruled out, it was found that $15.6 \%$ of patients had a history of a comorbid disease accompanying COPD (10). In another study including 50 male COPD patients without a comorbid disease and 20 healthy male control patients, no statistically significant difference was observed between the two groups in terms of the prevalence ( $24 \%$ in the COPD group and $10 \%$ in the control group) and severity of RLS. Moreover, in the evaluation of the relationship between RLS and the use of bronchodilator drugs and long-term oxygen therapy used in the treatment of COPD patients, while no statistically significant difference was found between the use of long-acting beta- 2 agonist, theophylline, and inhaler steroid drug and the incidence of RLS, there was a statistically significant relationship between the use of anticholinergic drugs and RLS (91.6\% in COPD patients with RLS and $57.8 \%$ in COPD patients without RLS) (12). In a recent study that investigated sleep disorders, fatigue, and RLS in 104 COPD patients by comparing them with the control group patients, 32 patients $(30.8 \%)$ were detected to have RLS. It was reported that $26(81.3 \%)$ of these patients had moderate-severe RLS. It was found that RLS symptoms began after the age of 40 years in most of the patients and RLS patients had lower creatinine levels, poorer sleep quality, more fatigue, and more depressive symptoms. Moreover, ferritin levels and the severity of dyspnea were found to be correlated with the severity of RLS symptoms (11). In our study, RLS was detected in 17 (34\%) of 50 COPD patients without a comorbid disease and a history of drug usage that could cause RLS. This rate is quite higher than the rate of $3.19 \%$ (14) seen in Turkish soci- ety. In addition, our study revealed that the duration of disease was longer and the number of hospitalizations within the last one year was higher in COPD patients with RLS. Moreover, patients with RLS were observed to have lower spirometric values. When patients were analyzed according to the mMRC dyspnea scale and CAT test results, it was found that mMRC dyspnea scale results were not different between the groups, but the CAT test results were significantly higher in the RLS group.

The basic pathophysiological mechanisms of RLS development in COPD are unknown. RLS was associated with severe hypoxia and hypercapnia in two studies, and in one of these studies, it was found to be associated with the severity of airway obstruction $(10,19)$. Moreover, it was reported that RLS was more frequent in patients with longer follow-up periods for $\operatorname{COPD}(9,10)$. In our study, the duration of disease was longer and obstruction was more severe in patients with RLS. However, although the levels of $\mathrm{PaO}_{2}$ and $\mathrm{SaO}_{2}$ were lower in patients with RLS, this difference was not found to be statistically significant. The levels of $\mathrm{PaCO}_{2}$ were similar in both groups. Hence, the data obtained in our study do not support the assumption that hypoxia and hypercapnia are related to RLS. Instead, they suggest that RLS is associated with the severity and duration of COPD.

The exact cause of RLS is still controversial. According to the data obtained from imaging studies, clinical measurements, and animal models, the dopaminergic system has the key role in the pathogenesis of RLS. Dopamine is a neurotransmitter that has important functions in the central nervous system (CNS). It has a circadian rhythm, and it peaks a few hours before waking up and at mid-day $(20,21)$. A dramatic response to dopaminergic agents supports the assumption that RLS is a disorder associated with CNS rather than the peripheral nervous system. Electrophysiological studies evaluating the pathophysiological role of the peripheral nervous system in RLS revealed that a stimulative response to the median and tibial nerves is normal, and thus, RLS is not a primary sensorimotor disease. It is thought that the stimulation of RLS in patients with peripheral neuropathy can be associated with impairment in the sensorial stimuli sent to the dopaminergic system. Sensorial stimuli can trigger the pathological activation of movement generators that have a low threshold due to neurochemical impairments. It is thought that these generators are presumably included in spinal dopaminergic cells or formatio reticularis in the spinal cord $(22,23)$. COPD is accepted to be a systemic disease, and CNS may be affected at the advanced stage of the disease (especially the brain stem). Depending on the involvement of CNS, pathological activation of the dopaminergic system can occur and the rhythm of the dopaminergic system can be impaired. This can be a possible mechanism that causes RLS to develop in COPD. However, pathophysiological studies are needed for the determination of its exact cause.

Sleep disorders associated with COPD have an important effect on life quality and the health state in these patients (24). Insomnia and sleep-related complaints in COPD cases are reported to be seen at high rates varying from $12 \%$ to $49 \%$ (25). Some factors such as disease symptoms, drugs that are used, disease-related anxiety, hypoxia, and hypercapnia are the primary factors that decrease sleep duration and quality (12). Cavalcante et al. (11) found in their study that poor sleep quality was one of the important problems in COPD patients and that there was a strong relationship between poor sleep 
quality and the severity of dyspnea and low creatinine levels. The relationship between impaired sleep quality and RLS was evaluated in the study of Lo Coco et al. (10). They detected that ESS values were higher in COPD patients with RLS than in the control group and in COPD patients without RLS, and they reported that RLS might be one of the factors decreasing sleep quality in COPD patients. In our study, sleep quality was observed to be poorer (high PSQI values) and daytime excessive sleepiness was higher (high ESS values) in COPD patients with RLS compared to those without RLS. Furthermore, it was detected that as the duration and severity of the disease increased (low RFT and ABG values), sleep quality was impaired. Also, increased dyspnea severity (according to $\mathrm{mMRC}$ ) and impaired life quality (according to (AT) were found to be significantly associated with poor sleep quality and increased daytime sleepiness.

Our study has some limitations. First, the number of patients was relatively low. Moreover, it is known that many different factors affect sleep quality in COPD patients. In this study, sleep quality was evaluated with PSQI and ESS questionnaires without performing a polysomnography. Therefore, not having evaluated other factors that can affect sleep structure and quality, particularly obstructive sleep apnea syndrome that is frequently seen in COPD patients, is an important limitation of our study. Another limitation is that the possible relationship between RLS and drugs used in the treatment of COPD was not evaluated in the study. Finally, our study did not include a healthy control group.

\section{CONCLUSION}

In our study, it was revealed that the prevalence of RLS was prominently higher in COPD patients than in the normal population and that there was an important relationship between the presence of RLS and poor sleep quality and excessive daytime sleepiness. Another important result obtained in our study is that as long as the duration and activity of the disease increase in COPD, sleep quality is impaired. In particular, COPD patients with complaints of frequent awakening and difficulty in falling and staying asleep should be examined for RLS carefully.

Ethics Committee Approval: Ethics committee approval was received for this study from the ethics committee of Firat University.

Informed Consent: Written informed consent was obtained from patients who participated in this study.

Peer-review: Externally peer-reviewed.

Author Contributions: Concept - E.I., T.T.; Design - E.I., T.T., C.Ö.; Supervision - E.I.., T.T.; Resources - E.I.; Materials - E.I.; Data Collection and/or Processing E.I.; Analysis and/or Interpretation - E.I., T.T., C.Ö.; Literature Search - E.I., T.T.; Writing Manuscript - E.I., T.T., C.Ö.; Critical Review - E.I., T.T., C.Ö.

Conflict of Interest: No conflict of interest was declared by the authors.

Financial Disclosure: The authors declared that this study has received no financial support.

\section{REFERENCES}

1. Earley CJ, Silber MH. Restless legs syndrome: understanding its consequences and the need for better treatment. Sleep Med 2010; 11:807-15. [CrossRef]

2. Ohayon MM, Roth T. Prevalence of restless legs syndrome and periodic limb movement disorder in the general population. J Psychosom Res 2002; 53: 547-54. [CrossRef]
3. Allen RP, Picchietti D, Hening WA, Trenkwalder C, Walters AS, Montplaisi J; Restless Legs Syndrome Diagnosis and Epidemiology workshop at the National Institutes of Health; International Restless Legs Syndrome Study Group. Restless legs syndrome: diagnostic criteria, special considerations, and epidemiology. A report from the restless legs syndrome diagnosis and epidemiology workshop at the National Institutes of Health. Sleep Med 2003; 4: 101-19. [CrossRef]

4. Garcia-Borreguero D, Egatz R, Winkelmann J, Berger K. Epidemiology of restless legs syndrome: the current status. Sleep Med Rev 2006; 10: 153-67. [CrossRef]

5. Allen RP, Earley CJ. The role of iron in restless legs syndrome. Mov Disord 2007; 22: S440-8. [CrossRef]

6. Hornyak M, Feige B, Voderholzer U, Philipsen A, Rienmann D. Polysomnography findings in patients with restless legs syndrome and in healthy controls: a comparative observational study. Sleep 2007; 30: 861-5.

7. Kutty K. Sleep and chronic obstructive pulmonary disease. Curr Opin Pulm Med 2004; 10: 104-12. [CrossRef]

8. Bülbül Y. Kronik Obstrüktif Akciğer Hastalığında Uyku Sorunları. Güncel Göğüs Hastalıkları Serisi 2013; 1: 80-5.

9. Kaplan $\mathrm{Y}$, Inonu H, Yilmaz A, Ocal S. Restless legs syndrome in patients with chronic obstructive pulmonary disease. Can J Neurol Sci 2008; 35: 352-7. [CrossRef]

10. Lo Coco D, Mattaliano A, Lo Coco A, Randisi B. Increased frequency of restless legs syndrome in chronic obstructive pulmonary disease patients. Sleep Med 2009; 10: 572-6. [CrossRef]

11. Cavalcante AG, de Bruin PF, de Bruin VM, Pereira ED, Cavalcante MM, Nunes $\mathrm{DM}$, et al. Restless legs syndrome, sleep impairment, and fatigue in chronic obstructive pulmonary disease. Sleep Med 2012; 13: 842-7. [CrossRef]

12. Başer ZM, Uçar ZZ, Mertoğlu A, Kıraklı C, Özacar R. Restless legs syndrome in COPD patients without accompanying disease. Erciyes Med J 2012; 34: 24-8. [CrossRef]

13. Vestbo J, Hurd SS, Agusti AG, Jones PW, Vogelmeier C, Anzueto A, et al. Global strategy for the diagnosis, management and prevention of chronic obstructive pulmonary disease. NHLBI/WHO Global Initiative for chronic obstructive pulmonary disease (GOLD). Workshop summary. Am J Respir Crit Care Med 2013; 187: 347-65. [CrossRef]

14. Sevim S, Dogu O, Camdeviren H, Bugdayci R, Sasmaz T, Kaleagasi H, et al. Unexpectedly low prevalence and unusual characteristics of RLS in Mersin, Turkey. Neurology 2003; 6: 1562-9. [CrossRef]

15. Walters AS, LeBrocq C, Dhar A, Hening W, Rosen R, Allen RP, et al. International Restless Legs Syndrome Study Group. Validation of the International Restless Legs Syndrome Study Group rating scale for restless legs syndrome. Sleep Med 2003; 4: 121-32. [CrossRef]

16. Buysse DJ, Hall ML, Strollo PJ, Kamarck TW, Owens J, Lee L, et al. Relationships between the Pittsburgh Sleep Quality Index (PSQI), Epworth Sleepiness Scale (ESS), and clinical/polysomnographic measures in a community sample. J Clin Sleep Med 2008; 4: 563-71.

17. Ağargün MY, Kara $H$, Anlar O. Translation and validation of the Turkish version of the Pittsburg Sleep Quality Index (PSQI). Türk Psikiyatri Dergisi 1996; 7: 107-15.

18. Izci B, Ardic S, Firat H, Sahin A, Altinors M, Karacan I. Reliability and validity studies of the Turkish version of the Epworth Sleepiness Scale. Sleep Breath 2008; 12: 161-8. [CrossRef]

19. Spillane JD. Restless legs syndrome in chronic pulmonary disease. $\mathrm{Br}$ Med J 1970; 4: 796-8. [CrossRef]

20. Trenkwalder C, Paulus W. Why do restless legs occur at rest?-pathophysiology of neuronal structures in HBS. Neurophysiology of RLS (part 2). Clin Neurophysiol 2004; 115: 1975-88. [CrossRef]

21. Ondo WG, He Y, Rajasekaran S, Le WD. Clinical correlates of 6-hydroxydopamine injections into Al1 dopaminergic neurons in rats:a possible model for restless legs syndrome. Mov Disord 2000; 15: 154-8. [CrossRef] 
22. Rijsman RM, de Weerd AW. Secondary periodic limb movement disorder and restless legs syndrome. Sleep Med Rev 1999; 3: 147-58. [CrossRef]

23. Mosko SS, Nudleman KL. Somatosensory and brainstem auditory evoked responses in sleep-related periodic leg movements. Sleep 1986; 9: 399-404.
24. Valipour A, Lavie P, Lothaller H, Mikulic I, Burghuber OC. Sleep profile and symptoms of sleep disorders in patients with stable mild to moderate chronic obstructive pulmonary disease. Sleep Med 2011; 12: 367-72. [CrossRef]

25. Kutty K. Sleep and chronic obstructive pulmonary disease. Curr Opin Pulm Med 2004; 10: 104-12. [CrossRef] 